\title{
URBANO-DIGITAL-URBANO: \\ PODER SIMBÓLICO E EFEITOS DE LUGAR NAS INTERVENÇÕES DE URBANOGRAFIA NO INSTAGRAM
}

Thiago de Andrade Morandi ${ }^{1}$

\section{Introdução}

A urbanografia ou escrita das ruas é uma das formas de denominação da arte urbana, que incluí grafites, pichações, lambe-lambe, projeções, etc. Essas intervenções efêmeras carregam muitas vezes em sua essência enunciações de discursos de lutas políticas e ideológicas, reafirmando ou transgredindo poderes simbólicos que estão constituídos na sociedade.

Nas palavras de Bourdieu (1989), “o poder simbólico é, com efeito, esse poder invisível o qual só pode ser exercido com a cumplicidade daqueles que não querem saber que lhe estão sujeitos ou mesmo que o exercem" (BourdieU, 1989: 7). O poder simbólico, portanto, é uma forma transformadora que legitima outras formas de poder, desde que seus discursos sejam produzidos pelos agentes de enunciação, sejam recebidos e reconhecidos como legitimados.

A arte urbana pode ser caracterizada de diversas formas e estilos, pode compreender muitos processos de criação, que envolvem técnicas e modos de se fazer intervenção nas cidades. Na visão de Silva (2014), a arte urbana "adquire um aspecto urbano e se associa principalmente a mensagens deixadas sobre muros e paredes das cidades ou sobre diferentes objetos dos cidadãos. " (Silva, 2014: 24), o autor adota a palavra "grafite", com a terminação "te" para denominar as mais diversas formas de se criar arte urbana, para Silva (2014) ao utilizar a etimologia latina na palavra, ele propõe expandir as possibilidades de inclusão e de abordagens das mesmas.

Silva (2014) destaca ainda que

[...] o grafite alimenta-se de momentos históricos, e seus realizadores anônimos são os agentes que, com certas características pessoais ou grupais, materializam, através das escritas ou representações ocasionais, desejos e frustações de uma coletividade, ou, ainda, exaltam formas que retomam ou questionam seus territórios sociais. (Silva, 2014: 23).

\footnotetext{
${ }^{1}$ Pontifícia Universidade Católica de Minas Gerais (PUC Minas). Email: morandi.pesquisa@gmail.com. ORCID id: https://orcid.org/0000-0001-7265-7288
} 
Armstrong (2019) por sua vez utiliza o uso de "street art" e "urban art" (arte urbana) de forma diferente, para o autor a street art são as intervenções in loco, nas ruas, nas paredes, e arte urbana é uma apropriação mercantil da mesma, que está na rua.

\begin{abstract}
Em um nível, a arte de rua é o grafite mercantilizado. A cunhagem da frase 'arte de rua', que começou a circular em meados da década de 1990, poderia ser lida como a cooptação e reformulação do graffiti, na tentativa de torná-lo socialmente mais aceitável, para vendê-lo. Qualquer subcultura que existe apesar do capitalismo é inerentemente irresistível ao capitalismo, que está sempre em busca de oportunidades para monetizar, comercializar e lucrar. O graffiti estava se mostrando uma cultura durável. Era hora de domá-lo, fumigá-lo da criminalidade, inverter a retórica anti-estabilização e vendê-lo de volta às pessoas como uma decoração contemporânea. (Armstrong, 2019: 16) (Tradução do autor) $)^{2}$
\end{abstract}

Na minha visão, não concordo com a abordagem de Armstrong no ponto de vista que o uso de "arte urbana" mercantiliza a intervenções, mas concordo que em relação ao discurso, é sim, uma forma de tornar o grafite uma arte mais aceitável na sociedade. Digo isso, pois, se adotássemos essa visão mercantilista na análise que realizo nas redes sociais, a inserção do grafite no Instagram seria uma "arte urbana". Não excluo o fato que isso acontece em alguns casos, mas não dá para generalizar, o que mais se vê são inserções de grafiteiros e pichadores no Instagram em busca de um novo espaço para se exibirem suas intervenções, ganhando, na verdade, uma nova parede de exposição.

Atualmente, um expressivo número de pessoas que realizam intervenções nas ruas, fotografam e postam suas obras em redes sociais, principalmente no Instagram. Nesta plataforma exibem, observam buscam validar (direta e indiretamente) este poder simbólico das artes urbanas e o discurso que as mesmas carregam.

Outro ponto abordado neste texto são os efeitos de lugar e de estigmatização territorial presentes no poder simbólico inserido nas intervenções urbanas, e como seus impactos interferem diretamente na escolha do local a ser feita a intervenção e como os mesmos são apropriados na concepção de novos capitais simbólicos.

Como recorte de pesquisa são analisadas 15 \#hashtags que são observadas no Instagram desde 2019, quantificando-as em sua presença na plataforma em forma de postagens e também algumas perspectivas analíticas qualitativas de alguns perfis de grupos e indivíduos que realizam suas intervenções urbanas na região de Belo

\footnotetext{
${ }^{2}$ On one level, street ar tis graffiti commodified. The coining of the frase 'street art', wich began to circulate in the mid-to late 1990s, could be readas the co-option and rebranding of graffiti, na attempt to make it more socially acceptable, to sell it. Any subculture that exists in spite of capitalismo is inherently irresistible to capitalismo, who are Always seeking opportunities to monetize, trade and profit. Graffiti was proving a durable culture. It was time to tame it, fumigate it of criminality, invert the antiestabilishment rhetoric, and sellit back to people as contemporary decor. (Armstrong, 2019: 16).
} 
Horizonte. A técnica netnográfica utilizada nesta pesquisa está inserida na extração dos dados visuais que estão sendo observados.

Em geral, as metodologias de pesquisa visual tendem mais ao exploratório do que aos confirmatório. Ou seja, as metodologias visuais não são tão empregadas como método de coleta de dados de dimensão e forma predeterminadas que vão confirmar ou refutar uma hipótese previamente postulada, mas sim como método destinado a levar o pesquisador a esferas que ele pode não ter considerado e em direção a descobertas que não tinham sido previstas. (Banks, 2009: 24)

Inicialmente este breve estudo não traz de fato uma pergunta de pesquisa em si, mas tem por objetivo apresentar algumas observações realizadas na fase de exploração de uma investigação de doutorado que pretende responder duas questões principais. ${ }^{3}$

\section{Espaço Social e estigmatizarão territorial no grafite e pichação/pixação}

Bourdieu defende no conjunto de suas obras e estudos que as classes sociais não eram definidas somente pela detenção de bens econômicos, mas sim por valores intrínsecos de comportamento, ou seja, membros de uma mesma classe social tinham valores culturais parecidos, assim como seus modos de falar, os gostos, as roupas, a visão de arte, lazer e etc. De modo geral, o autor notou que as altas classes tinham um grande apreço para a poesia, arte, filosofia e frequentavam lugares clássicos, enquanto a classe trabalhadora gostava de ler romances, revistas, fazer apostas e geralmente frequentava shows musicais.

A classe ou subclasse era determinada mais pelo grupo que se reconheciam em si do que pelo valor econômico, ou seja, ao compartilhar o mesmo habitus ${ }^{4}$ eles passavam a gostar de uma mesma coisa e isso os dava um determinado senso particular de espaço. A criação deste habitus não se dá de forma particular, mas através da interação das mentes subjetivas nas estruturas ao seu redor. Essas interações acontecem

\footnotetext{
${ }^{3}$ Qual é a importância do registro fotográfico e videográfico das pichações e grafites criados e produzidos pelos autores dessa arte, de sua gravação em redes sociais ou em outras formas de registro? E qual é a relação entre os espaços dos muros/paredes e os espaços escolhidos para a fixação da sua criação artística e seus efeitos para alimentar e retroalimentar a capacidade criativa no cenário das cidades?

4 É o sistema de disposições incorporadas e adquiridas pelo individuo através do convívio de sociabilidade. Este sistema é objetificado e atualizado constantemente, pois, o indivíduo incorpora ao seu modo de ser outros gestos, vocabulários e etc.
} 
com o acumulo de capitais que são adquiridos na interação social. Existem vários tipos de capital ${ }^{5}$ : cultural, econômico e social.

Existe ainda o capital simbólico, que representa o conjunto de todas as outras formas de capital refletidas no seu modo de vida, este capital é constituído nas estruturas sociais que são estruturadas com regras impostas aos grupos. Desde pequenos, os indivíduos crescem com regras e valores compreendidas no seu senso comum com a compreensão de que tais regras devem ser realmente da forma que são.

O poder simbólico como poder de constituir o dado pela enunciação, de fazer ver e fazer crer, de confirmar ou de transformar a visão do mundo e, deste modo, a acção sobre o mundo, portanto o mundo; poder quase mágico que permite obter o equivalente daquilo que é obtido pela força (física ou económica), graças ao efeito específico de mobilização, só se exerce se for reconhecido (Bourdieu, 1989: 14).

Este capital simbólico é construído socialmente nos indivíduos por meio do poder simbólico, “o poder simbólico é, com efeito, esse poder invisível o qual só pode ser exercido com a cumplicidade daqueles que não querem saber que lhe estão sujeitos ou mesmo que o exercem." (Bourdieu, 1989: 7-8).

Todos estes capitais, principalmente o poder simbólico estão diretamente ligados ao espaço social, que determina os efeitos de lugar do indivíduo. Para Bourdieu (1997) o lugar é definido como o ponto do espaço físico em que ocupamos.

Efetivamente, o espaço social se retraduz no espaço físico, mas sempre de maneira mais ou menos confusa: o poder sobre o espaço que a posse do capital proporciona, sob suas diferentes espécies, se manifesta no espaço físico apropriado sob a forma de uma certa relação entre a estrutura espacial da distribuição dos agentes e a estrutura espacial da distribuição dos bens ou dos serviços, privados ou públicos. (Bourdieu, 1997: 160)

Em outras palavras podemos dizer que o espaço social é o campo fisicamente objetivado, estruturado de forma hierárquica através dos capitais que os indivíduos adquirirem, e que por meio de seus hábitos e conduta os permitem transitar entre diversos lugares. $\mathrm{O}$ acumulo de capital nos permite ser aceito em locais em que nem todos tem acesso, permite que possamos frequentar lugares restritos para um determinado grupo, que por sua vez detém de certos capitais. Desta forma alguns

\footnotetext{
${ }^{5}$ De forma muito sucinta, o capital é um conjunto de ativos de conhecimento adquiridos na interação social. Como capital cultural entende-se qualificações intelectuais adquiridas no âmbito escolar e familiar. Capital econômico é o conjunto de bens patrimoniais ou provenientes da força de trabalho. Capital social é proveniente dos contratos de relações sociais que exercemos com o convívio em sociedade.
} 
lugares são estigmatizados e consequentemente segregados territorialmente, geralmente por consequências de políticas públicas ou por interesses econômicos de pessoas com alto capital econômico.

Loïc Wacquant apresenta características de estigmatização em territórios,

[...]os efeitos da estigmatização territorial também se fazem sentir ao nível das políticas públicas. A partir do momento em que um lugar é publicamente etiquetado como uma zona de «não-direito» ou uma «cité fora da lei»e fora da norma, é fácil para as autoridades justificar medidas especiais, derrogatórias face ao direito e aos costumes, que podem ter como efeito quando não por objectivo - desestabilizar e marginalizar mais ainda os seus habitantes, submetê-los aos ditames do mercado de trabalho desregulado, torná-los invisíveis ou escorraçá-los de um espaço cobiçado. (Wacquant, 2006: 30)

Essas marcas são impostas por quem rege as regras de conduta, sejam interpessoais ou em grupos de indivíduos. Isso faz com que determinas regiões ou espaços carreguem em si estigmas que os caracterizam como locais perigosos ou de valores duvidosos, e como dito anteriormente, geralmente devido às políticas públicas e interesses do capital econômico.

Esteticamente alguns destes locais que detém o rótulo de estigma são lugares com um grande número de intervenções urbanas, como acontece na região do viaduto Santa Teresa em Belo Horizonte. Estética também vista em características simbólicas utilizadas cenograficamente em alguns filmes, o Filme Coringa (2019) ${ }^{6}$ por exemplo, tem na maior parte de suas paisagens urbanas de Gotham City (uma representação literária de uma cidade parecida com Nova Yorque na década de 1970) um grande número de intervenções urbanas.

É possível notar, portanto, que a estética das intervenções urbanas, pincipalmente da pichação e pixação, tentem a contribuir para a rotulação de espaços sociais que são estigmatizados territorialmente. Essa rotulação se dá, sobretudo por meio da indústria cultural e da construção social da realidade (Berger; Luckmann, 2007) na mídia, que recorta determinados fragmentos de acontecimentos para definir em sua linha editorial o que é ou não notícia.

Por outro lado, existem o uso da estética do grafite com a finalidade de valorizar um determinado espaço social como por exemplo no lançamento de um empreendimento imobiliário em São João del-Rei.

\footnotetext{
${ }^{6}$ Coringa, dirigido por Todd Phillips e lançado em 2019, retrata como o comediante Arthur Fleck se torna um dos vilões mais famosos de Batman, nos HQ's da DC Comics.
} 
Figura 1 - Propaganda de um empreendimento imobiliário em São João del-Rei (MG) ${ }^{7}$
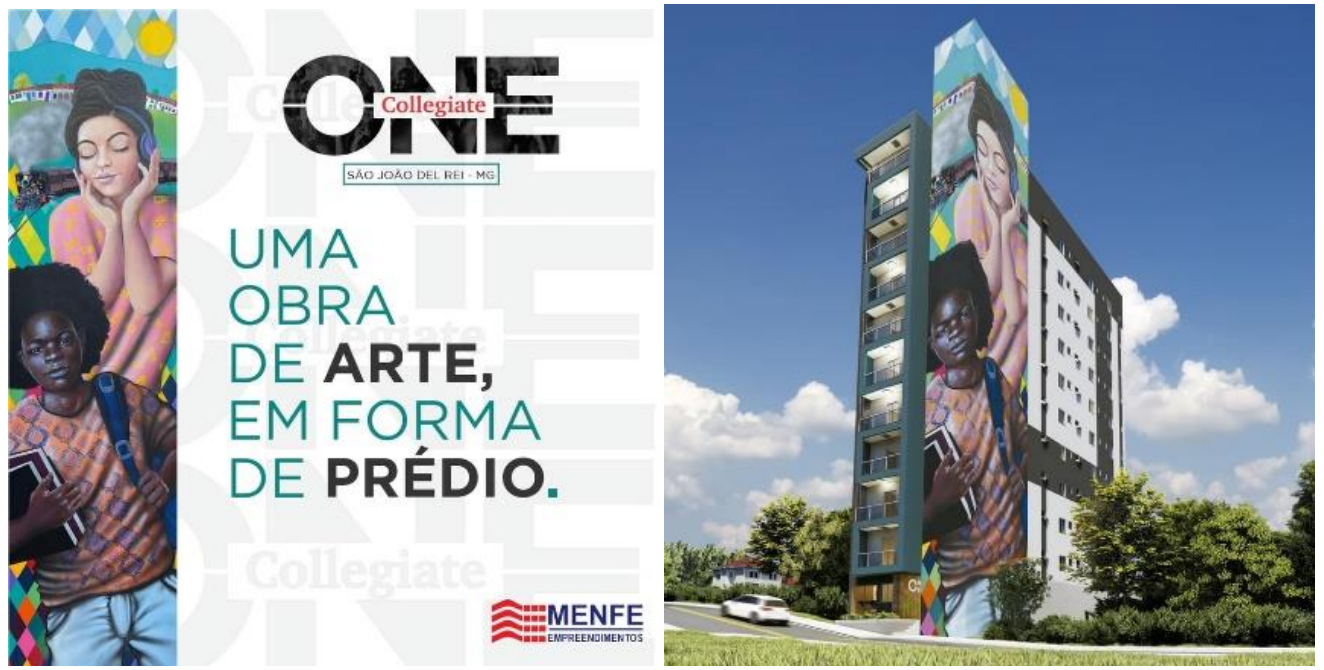

Fonte: Acervo do autor

É possível ainda, traçar um paralelo entre a estigmatizarão territorial e a detenção de capitais, uma vez que está ligado diretamente ao poder simbólico presente no espaço social.

\begin{abstract}
Inversamente, os que não possuem capital são mantidos à distância, seja física, seja simbolicamente, dos bens socialmente mais raros e condenados a estar ao lado das pessoas ou dos bens mais indesejáveis e menos raros. A falta de capital intensifica a experiência da finitude: ela prende a um lugar. (Bourdieu, 1997: 164).
\end{abstract}

Por outro lado, essa distância física de espaço social causada pala não detenção dos capitais simbólicos inspiram algumas dessas intervenções urbanas, como é visto em algumas pichações poéticas, e de cunho político, inseridas em prédios públicos, como por exemplo no edifício do Ministério do Trabalho e Emprego, que fica na Rua Curitiba, 832, no centro de Belo Horizonte.

No local, integrantes de Grife "Os Piores de Belô" escreveram na fechada do edifício a frase: "quando for roubar dinheiro público ver se esqueça que na sua conta tem a onra de um trabalho", que aparentemente é inspirada no trecho da música "Só Deus Pode Me Julgar", do MV Bill, que diz: "quando for roubar dinheiro público vê se não se esqueça/que na sua conta tem a honra de um homem".

\footnotetext{
${ }^{7} \mathrm{O}$ fato do uso do grafite como um instrumento de valorização do espaço é destaque em um informe publicitário do G1, portal de notícias da Globo. Disponível em: https://g1.globo.com/mg/zona-damata/especial-publicitario/menfe-empreendimentos/noticia/2020/12/01/a-inovacao-que-valoriza-acultura-e-a-diversidade.ghtml. Acesso em 11 maio 2021.

${ }^{8}$ A última palavra da pichação é algo como "emobonho", que não foi possível ler de forma precisa, portanto, omitimos ela da frase, pois não parece fazer sentido para compreensão da mesma.
} 
Figura 2 - Print extraído do perfil @ graffitibhz
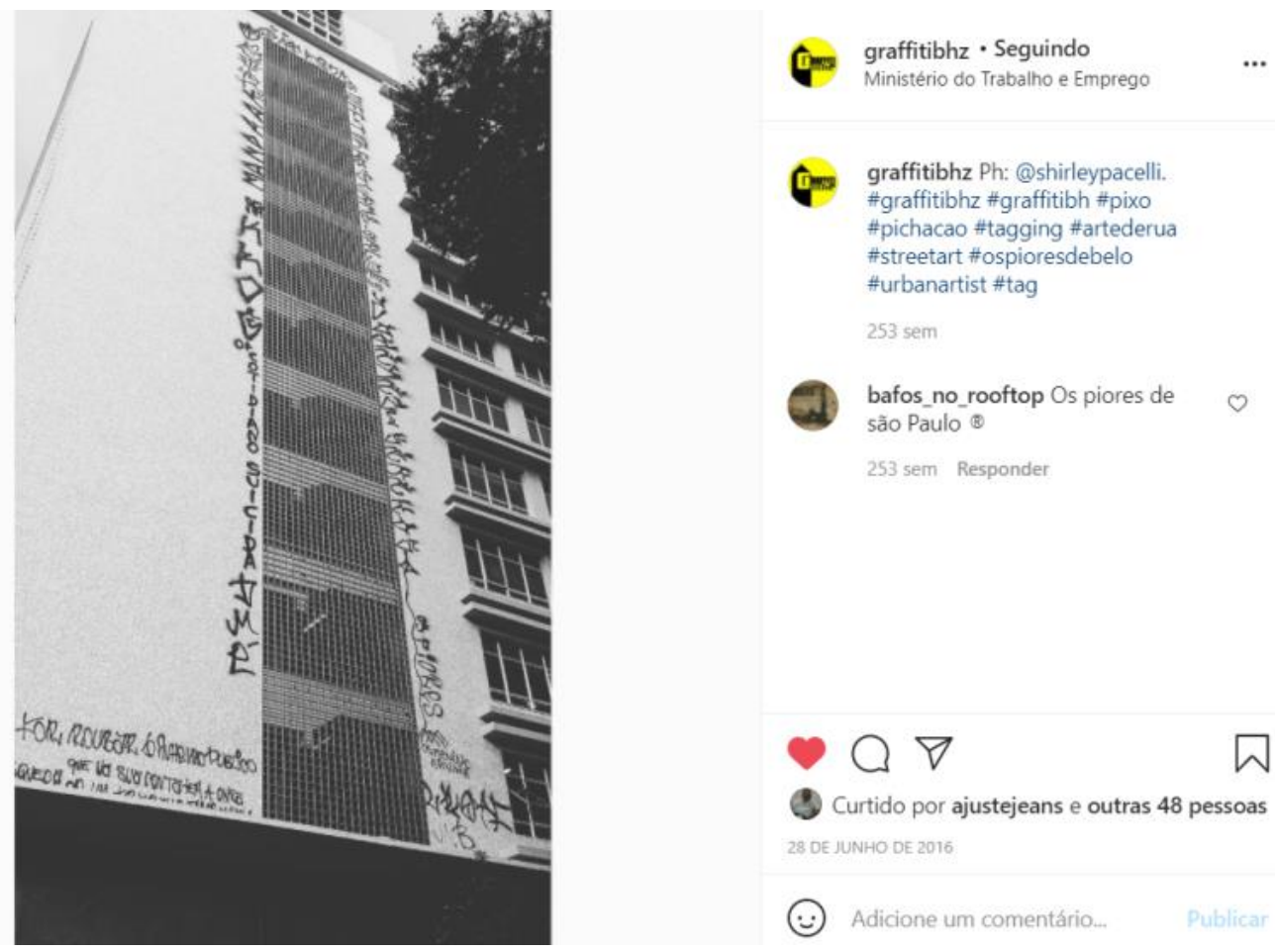

Fonte: Perfil @graffitibhz no instagram

Na imagem abaixo do Street View do Google Maps, capturada em abril de 2019, é possível visualizar a densa movimentação de indivíduos e veículos no local. O que representa o desejo dos pichadores em representar sua indignação para um grande número de indivíduos e sua luta para um maior reconhecimento no espaço social.

Figura 3 - Imagem retirada do Google Street View

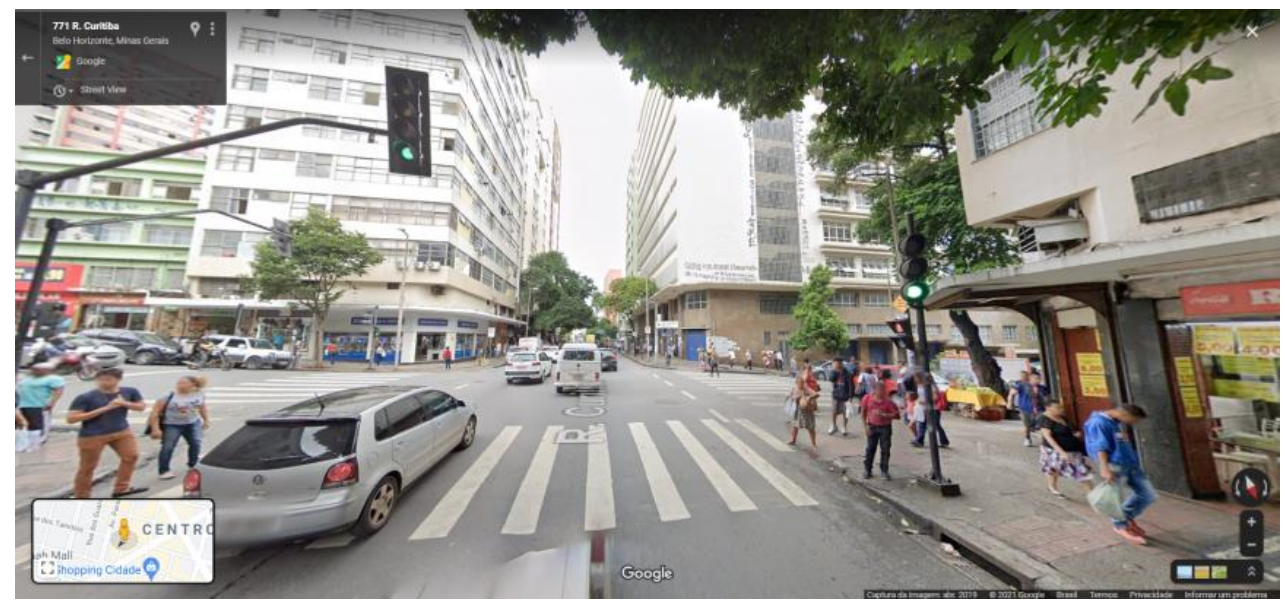

Fonte: Google Street View

As lutas pelo espaço podem também assumir formas mais coletivas, como é o caso daquelas que se desenrolam a nível nacional em tomo das políticas de 
habitação, ou daquelas que ocorrem a nível local, a propósito da construção e da distribuição de moradias sociais ou das escolhas em matéria de equipamentos públicos. (Bourdieu, 1997: 166).

Tais lutas coletivas são visíveis nas grifes que integram uma variedade de membros pichadores e pixadores, como no exemplo dos "Piores de Belô" (que realizaram a intervenção no Edifício do Ministério do Trabalho e Emprego) e do "Círculo Forte Brasil (CFB)". O CFB integra duas grifes "os + Fortes" e o "círculo vicioso", que tem dentre seus integrantes o Cripta Djan, pixador de São Paulo, que em uma entrevista, concedida a mim, disse ser uma das propostas do CFB criar uma "guerrilha política do pixo" para fazer uma "revolução coletiva politizada", por meio da estética e desafio que a pixação exige de seus integrantes. Em outra ótica esse tipo de luta coletiva pode ser vista como os corpos em assembleia, defendida por Judith Butler (2018) no livro "Corpos em aliança e a política das ruas: notas para uma teoria performativa da assembleia".

\section{Métodos de observação da arte urbana nas redes sociais}

O principal método utilizado nesta pesquisa está sendo a netnografia, utilizando análise de dados visuais como técnica de pesquisa nesta fase exploratória da minha investigação de Doutorado nas Ciências Sociais da PUC Minas, sendo realizada observando o Instagram, seus usuários e interações. A partir de uma observação que acontece desde 2019, foi possível levantar 15 \#hashtags que são utilizadas pelos usuários da rede social ao postarem suas fotografias. Após o levantamento quantitativo das \#hashtags são realizadas observação e análises qualitativas, buscando compreender como as postagens contribuem para os processos de criação de outras intervenções nas ruas.

Além das análises por meio dos dados visuais, utilizamos o que Armando Silva (2014) apresenta como uma das possibilidades de análise das escritas urbanas do grafite o que ele denomina de operações de modo progressivo, as dividindo em três frentes: 1. Objeto de exibição; 2. Observação por um sujeito; e 3. Olhar citadino. Sendo o 1. A forma como é exposta à intervenção, que têm como caráter principal a transgressão de regras ou ordens vigentes do estado através de suas leis e normas. O 2. o que se representa e o que se quer representar, pois, nem sempre o que se vê é exatamente o que o grafiteiro e/ou pichador deseja mostrar, ou seja, são enquadramentos que se dão em 
determinadas intervenções. Na prática, uma obra pode conter símbolos e representações que passam alguns códigos de mensagem para grupos específicos de pessoas. E 3. é o olhar cúmplice do ver, fotografar e compartilhar, são, principalmente, as postagens de anônimos em redes sociais, que se apropriam visualmente de uma obra de intervenção de arte na rua.

Percebei que existem ao menos 57 milhões de postagens sobre arte urbana no Instagram e que de 2019 para cá houve um crescimento em mais de 11 milhões de publicações na rede, que determinados grupos de indivíduos realizam suas intervenções motivados por acontecimentos políticos e utiliza o Instagram como uma nova parede de exibição. Além disso, é possível identificar na rede social todas às três operações de modo progressivo de Silva (2014).

Quadro 1 - Levantamento feito em 01 de maio de 2019, 1 de maio de 2020 e 31 de janeiro de 2021

\begin{tabular}{llll}
\hline HASHTAG & $\begin{array}{l}\text { QUANTIDADE } \\
\mathbf{2 0 1 9}\end{array}$ & $\begin{array}{l}\text { QUANTIDADE } \\
\mathbf{2 0 2 0}\end{array}$ & $\begin{array}{l}\text { QUANTIDADE } \\
\text { 31 JAN 2021 }\end{array}$ \\
\hline streetart & 46.145 .563 & 52.991 .115 & 57.163 .608 \\
\hline graffiti & 38.116 .525 & 43.270 .006 & 46.746 .213 \\
\hline grafite & 1.028 .453 & 1.197 .031 & 1.335 .728 \\
\hline vandal & 796.866 & 931.649 & 1.043 .001 \\
\hline arteurbana & 774.143 & 939.722 & 1.064 .329 \\
\hline artederua & 740.000 & 895.158 & 1.064 .329 \\
\hline pixo & 201.234 & 241.150 & 1.008 .044 \\
\hline lambelambe & 112.779 & 135.330 & 149.341 \\
\hline vandalismo & 106.307 & 142.196 & 170.343 \\
\hline pixação & 66.106 & 86.147 & 69.159 \\
\hline xarpi & 49.692 & 61.326 & 74.283 \\
\hline Pichação & 34.459 & 56.957 & 50.189 \\
\hline grapixo & 33.529 & 44.961 & \\
\hline
\end{tabular}


Fonte: Elaborado pelo autor

Partindo dessas 15 \#hashtags existem outras, como se fossem extensões das mesmas. Como proposta de realizar um recorte geográfico, na tentativa de entender este universo em um contexto menos extenso, utilizei as próprias \#hashtags do Instagram e incluí em algumas dessas a abreviação de Belo Horizonte, "BH". E observei, no dia 5 de fevereiro de 2021, que com a palavra \#streetartbh existem 2.142 postagens, sendo a maioria com a estética do grafite e algumas apropriações do mesmo, como no exemplo abaixo, em que o grafiteiro @ ramargama utiliza-se da estética do pixo (estilo próprio de São Paulo $)^{9}$ em uma xícara, que é comercializada pelo @ rua.streetshop por R $\$ 65,00$ em seu site.

Figura 4 - Print de uma postagem na rede social Instagram

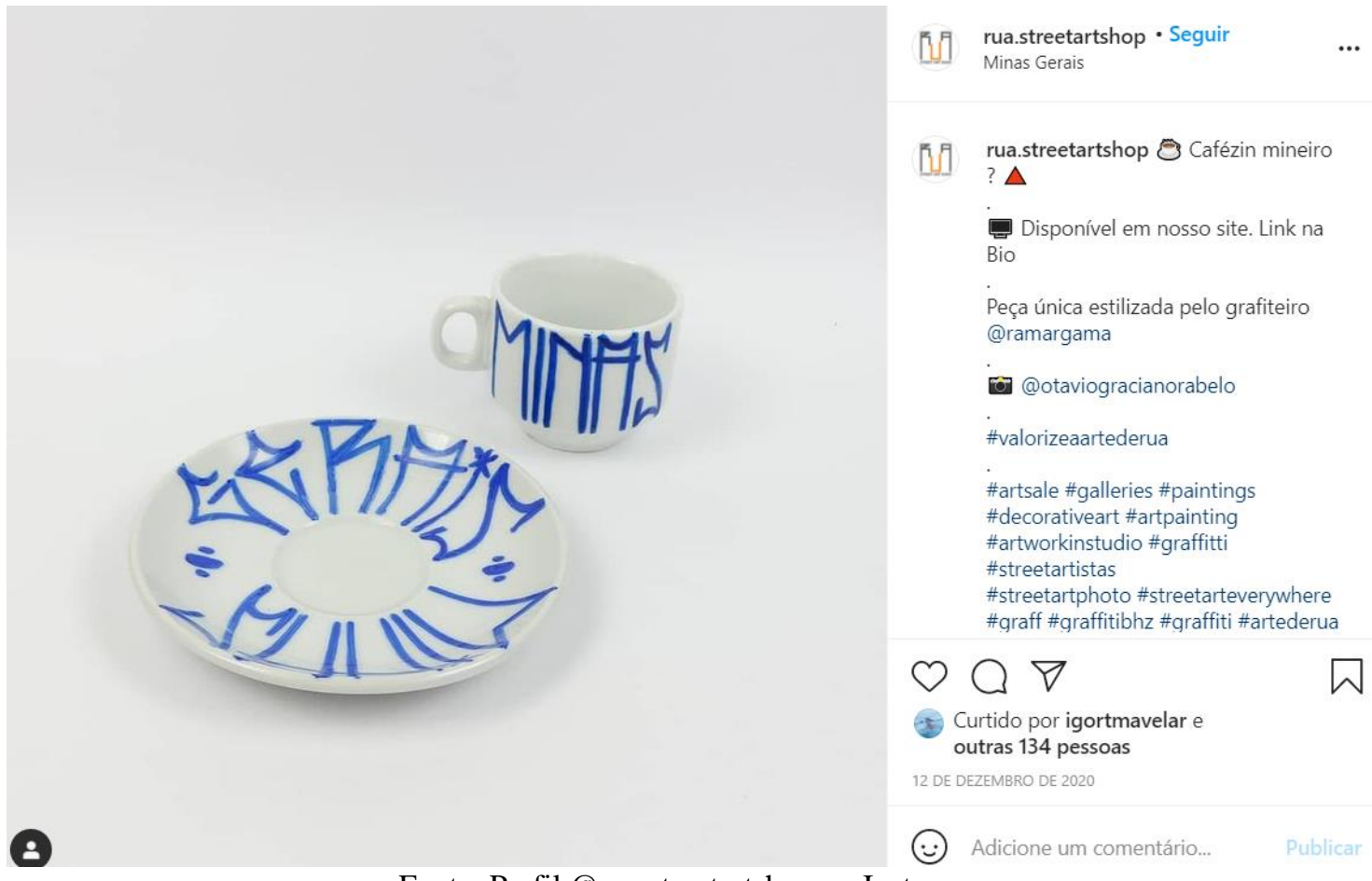

Fonte: Perfil @rua.streetartshop no Instagram

A \#graffitibh tem 7.546, com estética parecida com a \#Streetartbh, assim como a \#arteurbanabh, com 690 postagens e \#artederua, com 1.755. Outra informação

\footnotetext{
${ }^{9}$ Essas regionalidades por meio das diversas nomenclaturas que são tipicamente brasileiras são abordadas por mim no texto "Urbanografia e tecnologia: das paredes para a rede e de volta às paredes", que apresentei na $5^{\circ}$ edição do seminário de Artes Digitais em 2019.
} 
relevante que foi possível observar a partir desse levantamento foi a preferência pelo uso da palavra pixo (com X) ao invés de picho (com ch), algo que se aproxima muito do estilo paulista de escrita urbana, e, historicamente o estilo de urbanografia belorizontina, que é uma mescla dos estilos de São Paulo e do Rio de Janeiro.

O \#Pixobh tem 3.367 publicações, com a maioria na estética deste estilo de intervenção, com assinaturas e códigos próprios. Também observei a inserção de intervenções com cunho politico, que muito se aproxima da nomeclatura de picho (com $\mathrm{CH})$, como nos exemplos a seguir.

Figura 5 - postagens no Instagram com o uso da \#Pixobh

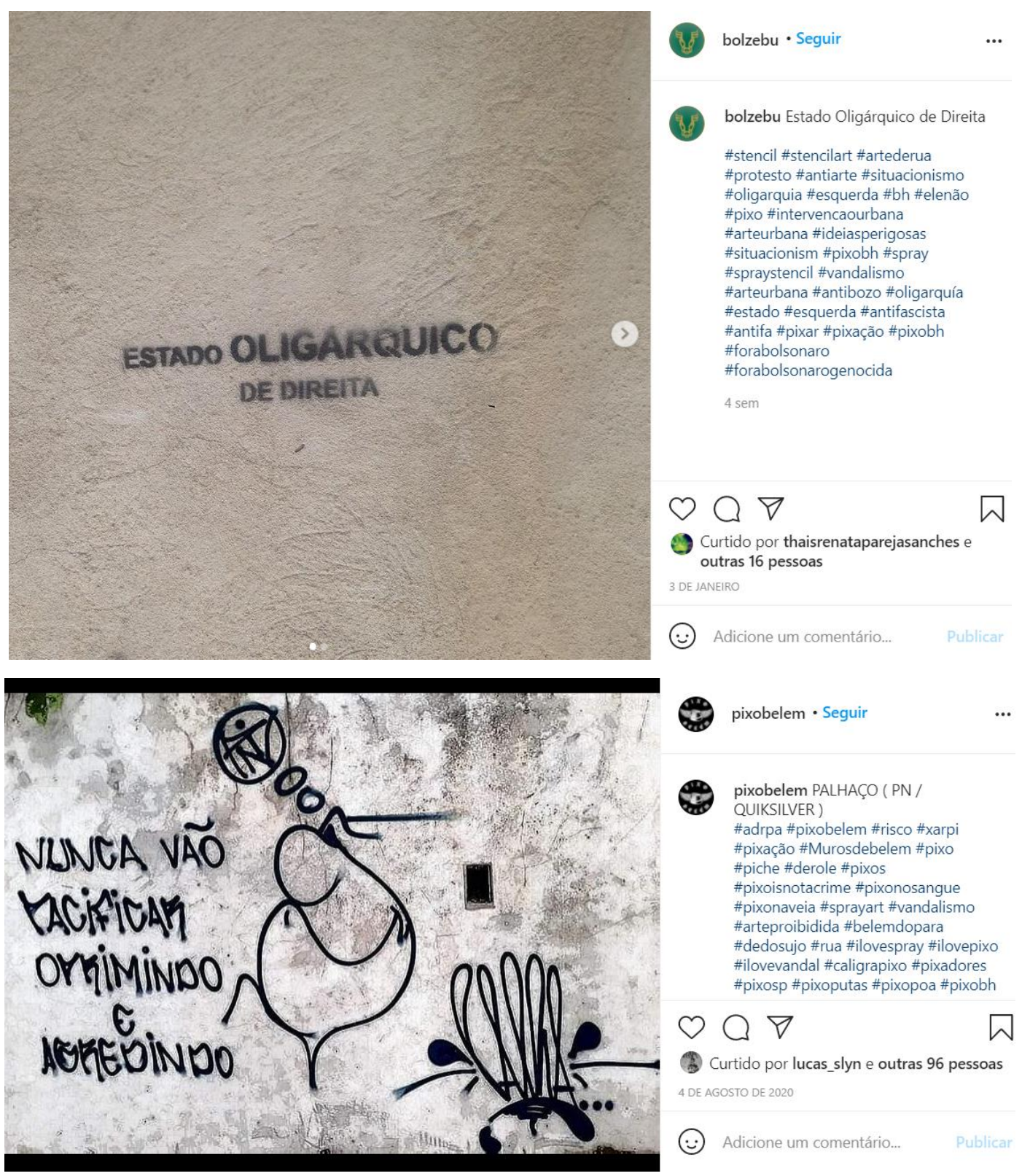

Fonte: Perfis@bolzebu e @ pixobelem no Instagram 
Por fim, temos também, \#lambelambebh com 505 postagens, \#pixacaobh com 495 e \#xarpibh com 263. Ilustrando de alguma forma a historicidade do estilo de arte urbana de Belo Horizonte.

\section{Considerações finais}

Esta pesquisa (ainda em andamento) é um recorte do estado exploratório que está sendo desenvolvido na minha investigação de doutorado, em que tenho utilizado da netnografia e antropologia visual para coletar estes dados iniciais para análise, principalmente com o uso de técnicas de análise de dados visuais.

É visível até o momento que a presença dos grafiteiros, pichadores e dos indivíduos que se apropriam da arte urbana por meio do olhar citadino é crescente na rede social Instagram, assim como os registros de intervenções que são realizadas em Belo Horizonte. Sendo possível observar as operações de modo progressivo propostas por Silva (2014)

Também é possível observar que tais usuários da capital mineira não utilizam tanto termos como \#vandal, \#vandalismo e outros termos parecidos, e que preferem o uso do pixo (com $\mathrm{X}$ ), o que me leva a crer que talvez seja necessário utilizar a denominação de "piXador" no lugar de "piCHador". Este fato me faz refletir ainda sobre a necessidade de uma melhor exploração em relação aos poderes simbólicos, que podem estar presentes na escolha do uso ou não de determinadas \#hashtags, uma vez que na capital mineira existe uma forte institucionalização de forças de segurança e poderes judiciários na tentativa de coibir intervenções urbanas, que nas suas visões são consideradas (enquadradas) como vandalismo e crime.

Outro fato observado foi que todas essas publicações contribuem para a criação de uma memória urbana digital, pois a princípio, uma intervenção de arte urbana seria efêmera, mas ao ser registrada e inserida no Instagram, ela torna-se de certa forma uma memória e permanece intacta enquanto postagem na rede social.

Um próximo passo desta pesquisa será a realização de entrevistas em profundidade com estes indivíduos, que por sua vez podem nos informar sobre a preferência do uso do termo, assim como essas interações no Instagram contribuem ou não para seus processos de criação.

\section{Referências}


ARMSTRONG, Simon. Street Art. Londres: Thames \& Hudson, 2019

BANKS, Marcus. Dados visuais para pesquisa qualitativa. - Porto Alegre: Artmed, 2009

BERGER, Peter L; LUCKMANN, Thomas. A construção social da realidade: tratado de sociologia do conhecimento. 27. ed. Petrópolis: Vozes, 2007

BOURDIEU, P. Efeitos de Lugar. In Bourdieu, P. (coord.) A miséria do mundo. Vozes, 1997.

BOURDIEU, Pierre. O Poder Simbólico. Rio de Janeiro: Ed. Bertrand Brasil, 1989.

BUTLER, Judith. Corpos em aliança e a política das ruas: notas para uma teoria performativa da assembleia. Rio de Janeiro: Civilização Brasileira. 2018.

MORANDI, Thiago de Andrade. Urbanografia e tecnologia: das paredes para a rede e de volta às paredes. (p. 254-263). In Anais do V Seminário de Artes Digitais 2019: um Congresso sobre as relações entre Arte, Ciência e Tecnologia após o advento das tecnologias digitais / Coordenação Pablo Gobira. -- Belo Horizonte: EdUEMG, 2019.

SILVA, Armando. Atmosferas urbanas: grafite, arte pública, nichos estéticos. Tradução de Sandra Trabucco Valenzuela. - São Paulo: Edições Sesc São Paulo, 2014

WACQUANT, Loïc. A estigmatização territorial na idade da marginalidade avançada. Sociologia: Revista da Faculdade de Letras da Universidade do Porto, vol. 16, 2006

Data de submissão: 16 de agosto de 2021

Data de publicação: 20 de dezembro de 2021 